\title{
Localisation of apoptosis and expression of apoptosis related proteins in the synovium of patients with rheumatoid arthritis
}

Masayasu Sugiyama, Tomoo Tsukazaki, Akihiko Yonekura, Sumihiro Matsuzaki, Shunichi Yamashita, Katsuro Iwasaki

\begin{abstract}
Objectives-To investigate whether apoptosis occurs in the synovium of rheumatoid arthritis (RA), and the intermediate molecules operating in this process. Methods-DNA fragmentation was detected by in situ nick end labelling (ISNEL) in the synovium of patients with RA $(n=11)$ and control patients with femoral neck fracture $(n=5)$. The expression of proteins p53, p21 WAF1/CIP1, c-myc, proliferating cell nuclear antigen (PCNA), and Bcl-2 was also examined by immunohistochemistry. Results-ISNEL positive synovial cells with apoptosis specific morphology were detected in extremely limited areas in only two RA synovial tissue specimens. Proteins p53, p21 WAF1/CIP1, and c-myc, known inducers of apoptosis or cell cycle arrest or both, were expressed in the sublining cells independent of ISNEL positive cells. PCNA, a marker for cell proliferation, was observed in the synovial lining cells. Bcl-2, an inhibitor of apoptosis, was expressed mainly in infiltrated lymphocytes and in parts of the sublining layer cells of RA; it also did not correspond with ISNEL staining.

Conclusions-Our findings indicate that RA synovial cells undergo apoptosis in addition to cell proliferation, but the frequency of apoptosis was very low. We suspect that the apoptotic process in the RA synovium may be suppressed by overexpression of Bcl-2. Although expressed proteins p53, p21 ${ }^{\mathrm{WAF} 1 / \mathrm{CIP}_{1}}$, and c-myc were present in the RA synovium, these protooncogenes are probably not implicated in the apoptotic process.
\end{abstract}

(Ann Rheum Dis 1996; 55: 442-449)

Apoptosis, or programmed cell death, is a fundamental process that occurs during morphogenesis and development of the immune system. ${ }^{12}$ Although the mechanism of apoptosis is still unclear, the process proceeds through the activation of an intrinsic cell suicide programme and exhibits specific morphology distinct from that associated with accidental cell death. ${ }^{3-5}$ It is now widely accepted that aberrant activation of apoptosis is the aetiological basis or one of the mechanisms of the progression of a variety of human diseases, including the development of cancer, auto- immune disorders, ischaemic injury, and degenerative diseases. ${ }^{67}$

Abnormal proliferation of synovial cells is an important event in the pathophysiology of rheumatoid arthritis (RA). During the acute phase of RA, the synovial cells grow rapidly, with progressive accumulation of proliferated cells. ${ }^{8}$ They also express various proto-oncogenes, such as c-myc, erb, and src, and frequently invade the cartilage tissue. ${ }^{9} 10$ These features resemble those of preneoplastic conditions, and suggest that dysregulation of the apoptotic machinery plays a role in the pathogenesis of RA: loss of the negative cell cycle control normally provided by apoptosis may initiate abnormal proliferation of synovial cells.

However, synovial cell death does seem to occur during the natural history of RA, counteracting cell proliferation: the synovial fluid often contains rice bodies, which are thought to be derived from the synovial tissue as a result of cell death. ${ }^{11}{ }^{12}$ Moreover, during the late stage of the disease, the proliferated synovial tissue is replaced by connective tissue. ${ }^{13}$ This suggests that apoptosis may also be involved in synovial cell death and in preventing the development of malignancy despite the neoplastic behaviour of synovial cells.

To investigate whether apoptosis occurs in the synovium of RA, we studied DNA fragmentation by the in situ nick end labelling (ISNEL) method. We also used immunohistochemical techniques to examine proteins related to apoptosis or cell cycle arrest to investigate the state of synovial cells with respect to apoptosis.

Patients and methods

PATIENTS AND TISSUES

Informed consent was obtained from each patient. Synovial tissue samples were obtained from 11 patients with RA at the time of joint replacement surgery of the hip or knee, or synovectomy of the wrist (table 1). Each patient satisfied the diagnostic criteria of the American College of Rheumatology. ${ }^{14}$ As a control, five synovial tissue samples were also obtained during joint replacement surgery for femoral neck fracture; fracture samples showing inflammatory synovitis on histopathological examination were excluded from the analysis. All patients with RA were treated with disease modifying antirheumatic drugs (DMARDs), and eight patients with active RA were receiving low dose prednisone (less than 
Table 1 Detailed information of each patient examined in the present study

\begin{tabular}{lllllll}
\hline Patient & Sex & Age $(y r)$ & Diagnosis & $\begin{array}{l}\text { Disease } \\
\text { duration }(y r)\end{array}$ & foint & Activity \\
\hline 1 & F & 68 & RA & 11 & Hip & Inactive \\
2 & F & 66 & RA & 12 & Hip & Active \\
3 & F & 62 & RA & 21 & Knee & Active \\
4 & M & 65 & RA & 23 & Hip & Active \\
5 & F & 32 & RA & 10 & Knee & Active \\
6 & F & 54 & RA & 27 & Knee & Active \\
7 & M & 59 & RA & 12 & Hip & Active \\
8 & F & 26 & RA & 7 & Hip & Active \\
9 & F & 37 & RA & 8 & Knee & Active \\
10 & F & 77 & RA & 3 & Hip & Inactive \\
11 & F & 67 & RA & 3 & Wrist & Inactive \\
12 & F & 79 & Fracture & - & Hip & - \\
13 & F & 86 & Fracture & - & Hip & - \\
14 & F & 83 & Fracture & - & Hip & - \\
15 & F & 79 & Fracture & - & Hip & - \\
16 & M & 26 & Fracture & - & Hip & - \\
\hline
\end{tabular}

$\mathrm{RA}=$ Rheumatoid arthritis. colour developed with appropriate secondary antibodies and NBT/BCIP. Because antibodies against p2 $1^{\text {WAF1/CIP1 }}$, c-myc, and CD68 were monoclonal, double staining was performed in a combination of $\mathrm{p} 53$ and $\mathrm{p} 21^{\mathrm{WAF} 1 / \mathrm{CIP} 1}, \mathrm{c}-\mathrm{myc}$, CD68, or ISNEL, and CD68 and p53 or ISNEL. Negative control experiments included replacement of the primary antibody with normal mouse or rabbit serum. Positive controls consisted of appropriate tissue samples such as the thymus, large intestine, salivary gland, and several malignant tumours.

\section{IN SITU NICK END LABELLING (ISNEL) FOR} APOPTOSIS

To examine whether apoptosis had occurred in synovial cells, we performed ISNEL staining, which allows in situ detection of DNA fragmentation as a result of the activation of endogenous endonuclease. ${ }^{3}$ In situ DNA fragmentation was performed using the in situ apoptosis detection kit (Oncor, Inc, Gaithersburg, USA), which uses a modified method of nick end labelling developed originally by Schmitz et al. ${ }^{16}$ Briefly, sections cleared of paraffin were digested with $20 \mathrm{mg} / \mathrm{ml}$ proteinase K (Sigma, St Louis, USA) for 15 minutes at room temperature. Endogenous peroxidase was deactivated with $2 \% \mathrm{H}_{2} \mathrm{O}_{2}$ in PBS for 10 minutes, followed by immersion in an equilibration buffer. Digoxigenin labelled deoxynucleotide was transferred to fragmented DNA by incubation with terminal deoxynucleotidyl transferase (TdT) for one hour at $37^{\circ} \mathrm{C}$. Sections were then incubated with secondary antidigoxigenin antibody conjugated with peroxidase for 30 minutes. After extensive washing, each section was colour developed by diaminobenzidine, and counterstained by methyl green. As a positive control, human large intestinal and tonsillar tissues, known to contain apoptotic cells, were added to the experimental specimens. Omission of TdT was used as a control for the degree of background staining. Laboratories, Burlingame, USA). Bcl-2 immunostaining was detected by the alkaline phosphatase-antialkaline phosphatase (APAAP) method. Sections were cleared of paraffin in xylene, dehydrated in a graded series of ethanol, and microwaved three times for five minutes in $0.01 \mathrm{~mol} / \mathrm{l}$ phosphate buffered saline (PBS). For detection of $\mathrm{Bcl}-2, \mathrm{p} 53$, and PCNA, the sections were microwaved in PBS containing $1 \%$ citric acid. The endogenous peroxidase was quenched with $0.3 \%$ hydrogen peroxide $\left(\mathrm{H}_{2} \mathrm{O}_{2}\right)$ in methanol for 15 minutes at room temperature. Slides were washed with PBS, and soaked in 3\% skimmed milk solution for 15 minutes to reduce non-specific binding. Sections were reacted with each antibody overnight at $4^{\circ} \mathrm{C}$ in a humid chamber, washed with PBS, and then incubated with appropriate secondary antibodies. Each section was colour developed by diaminobenzidine or NBT/BCIP, and counterstained with methyl green. For double staining studies, several sections were redehydrated, washed extensively with PBS, reacted again with CD68 antibody (a marker for macrophage) or p53 antibodies for 12 hours at $4^{\circ} \mathrm{C}$, and then

\section{EVALUATION}

The histological features and staining distribution of various markers were evaluated in consecutive sections of each tissue. An area of at least $1.5 \times 1.5 \mathrm{~cm}$ was analysed in each sample. Hyperplasia of the synovial lining cell layer was assessed on a semiquantitative scale: $1+=1-2$ cells thick; $2+=3-4$ cells thick; $3+=5-9$ cells thick; and $4+=>10$ cells thick. The overall degree of lymphocyte infiltration was assessed as follows: $0=$ no infiltration; $1+=$ minimal infiltration; $2+=$ moderately diffuse or aggregated infiltration; $3+=$ large number of aggregates, many demonstrating germinal centres. Staining by ISNEL and p53, p21 ${ }^{\mathrm{WAF} 1 / \mathrm{CIP} 1}$, c-myc, PCNA, and Bcl-2 antibodies was assessed for the tissue as a whole, and in association with specific cell types. Each tissue was assigned a score of $0-4+$ for the overall extent of staining associated with each antibody, as follows: $0=$ no staining above background; $1+=$ definite staining of $<1 \%$ 
Table 2 Histology and distribution of stained synovial cells with in situ nick end labelling (ISNEL) and immunohistochemistry, scored as described in Patients and methods

\begin{tabular}{lllllllll}
\hline Patient & $S L C$ & $I N F$ & ISNEL & $p 53$ & $p 21^{\text {WAFICIPI }}$ & $c$-myc & PCNA & Bcl-2 \\
\hline 1 & 3 & 2 & 0 & 2 & 3 & 1 & 1 & 1 \\
2 & 4 & 2 & 0 & 2 & 3 & 1 & 1 & 1 \\
3 & 3 & 2 & 0 & 0 & 1 & 1 & 1 & 0 \\
4 & 3 & 3 & 0 & 1 & 1 & 0 & 2 & 1 \\
5 & 3 & 3 & 0 & 1 & 2 & 1 & 2 & 1 \\
6 & 3 & 2 & 0 & 1 & 2 & 1 & 1 & 1 \\
7 & 4 & 1 & 1 & 1 & 2 & 1 & 1 & 1 \\
8 & 4 & 3 & 0 & 2 & 2 & 1 & 2 & 2 \\
9 & 3 & 3 & 0 & 1 & 1 & 1 & 1 & 1 \\
10 & 2 & 2 & 0 & 1 & 1 & 1 & 1 & 0 \\
11 & 3 & 1 & 1 & 1 & 1 & 0 & 1 & 1 \\
12 & 1 & 0 & 0 & 0 & 1 & 0 & 1 & 0 \\
13 & 2 & 0 & 0 & 0 & 1 & 0 & 1 & 0 \\
14 & 1 & 0 & 0 & 0 & 0 & 0 & 1 & 0 \\
15 & 1 & 0 & 0 & 0 & 1 & 0 & 1 & 0 \\
16 & 1 & 0 & 0 & 0 & 1 & 0 & 1 & 0 \\
\hline
\end{tabular}

SLC = Sublining layer cells; INF = infiltrated lymphocytes; PCNA = proliferating cell nuclear antigen.

of cells; $2+=$ staining of $1-5 \%$ of cells; $3+=$ staining of $5-20 \%$ of cells; $4+=$ staining of $>20 \%$ of cells.

\section{Results}

HISTOPATHOLOGICAL FEATURES AND IN SITU DNA FRAGMENTATION

All control synovial tissues from the hip joint exhibited no inflammatory cell infiltration, and the depth of the synovial membrane in these tissues was equivalent to or less than three cells thickness except in one sample, which was associated with a slight increase in synovial cells (patient 13, table 2). In contrast, hyperplasia of the synovial membrane and lymphocyte aggregation were identical in all RA samples.

Synovial cells stained with ISNEL were readily identifiable in only two $R A$ tissue samples and in none of the normal control tissues. In the two ISNEL positive cases, the number of positive cells was very small, and the distribution of positive cells differed in each. In synovial samples from patient 7 , a few sublining cells were stained sparsely with ISNEL (fig 1A), but the ISNEL positive synovial cells in the sample from patient 11 were clustered in a section of the papillary proliferated synovial lining layer (fig 1B). The most superficial synoviocytes just separating from their origin also stained with ISNEL. In these areas, we were able to identify several cells with apoptosis specific morphological changes such as halo ring formation, chromosomal condensation, nuclear fragmentation, and eosinophilic change of the cytoplasm (fig 1C). Neither the endothelial cells nor the infiltrated mononuclear cells stained with ISNEL or showed apoptotic morphology. Several ISNEL positive cells also reacted with CD68 antibody (a marker for macrophages), but very few of them were double stained by CD68 antibody (fig 2A).

IMMUNOHISTOLOGICAL FEATURES OF APOPTOSIS RELATED PROTEINS AND PNCA All RA synovial samples were stained with p21 $1^{\mathrm{WAF} 1 / \mathrm{CIP} 1}$ antibody. Intense staining of the cytoplasm was observed in large cells located in the sublining cell layer (fig 3A). The synovial lining cells in certain regions were also positive, but their immunoreactivity was much weaker than that of the sublining cells. There was no relationship between the distribution of $\mathrm{p} 21^{\mathrm{WAF} 1 / \mathrm{CIP} 1}$ and the scoring of histological findings. Staining with $\mathrm{p} 21^{\mathrm{WAF} 1 / \mathrm{CIP} 1}$ was also identified in all but one normal subject with weak immunoreactivity (data not shown).

Staining for p53 and c-myc was observed in 10 and eight RA samples, respectively, while no immunoreactivity to these molecules was observed in normal subjects. Immunoreactivity to p53 and c-myc was seen only in the cytoplasm of the sublining cells; synovial lining cells and infiltrated lymphocytes did not react with these antibodies (fig $3 \mathrm{~B}$ and $\mathrm{C}$, respectively). The expression of these proteins was also unrelated to the degree of synovial proliferation and lymphocyte infiltration. Although fewer cells stained with p53 or c-myc than with $\mathrm{p} 21^{\mathrm{WAF} 1 / \mathrm{CIP} 1}, \mathrm{p} 53$ and $\mathrm{c}-$ myc proteins seemed often to be expressed simultaneously with $\mathrm{p} 21^{\mathrm{WAF} 1 / \mathrm{CIP} 1}$. We therefore double stained sections that had stained with $\mathrm{p} 21^{\mathrm{WAF} 1 / \mathrm{CIP} 1}$ or c-myc, using p53 antibody, and found that a large number of cells stained with $\mathrm{p} 21^{\mathrm{WAF} 1 / \mathrm{CIP1}}$ or c-myc did not react with p53 antibody, though substantial numbers of cells were double stained (fig $2 \mathrm{~B}$, and data not shown). When $\mathrm{p} 53$ positive slides were double stained with CD68 to investigate whether $\mathrm{p} 53$ positive cells containing large amounts of cytoplasm were derived from macrophages, CD68 positive cells did not always coincide with p53 positive cells (fig $2 \mathrm{C}$ ).

Staining for PCNA was observed in the synovial lining cell layers with intranuclear staining of both normal and RA samples. PCNA positive synovial cells were distributed sparsely in normal subjects, while they tended to cluster within certain areas of the hypertrophic synovial lining layer in RA samples (fig 3D). Neither sublining cells nor infiltrated lymphocytes stained with PCNA.

Immunoreactivity against $\mathrm{Bcl}-2$ was readily identifiable in nine RA synovia, while synovial cells of normal subjects did not react with this antibody. Intense cytoplasmic staining for Bcl2 was observed mainly in lymphocytes forming lymphoid follicles and in sparsely infiltrated segments (fig 4). In addition, a substantial number of the sublining and stromal cells within the lymphoid follicles also showed faint but distinct immunoreactivity. In contrast, Bcl-2 expression was not detected in the epithelium, peripheral lymphocytes, synovial lining cells, or the major part of lymphoid cells in the normal lymph node (data not shown). In all samples examined, Bcl-2 positive cells were not present in regions where other proteins were expressed. The distribution of synovial cells stained with ISNEL also differed from the regions stained with $\mathrm{p} 21^{\text {WAF } 1 / C I P 1}, \mathrm{p} 53$, c-myc, PCNA, and Bcl-2.

\section{Discussion}

Under normal physiological conditions, synovial lining cells proliferate slowly and have a prolonged life span. ${ }^{17}{ }^{18}$ In the RA synovium, 

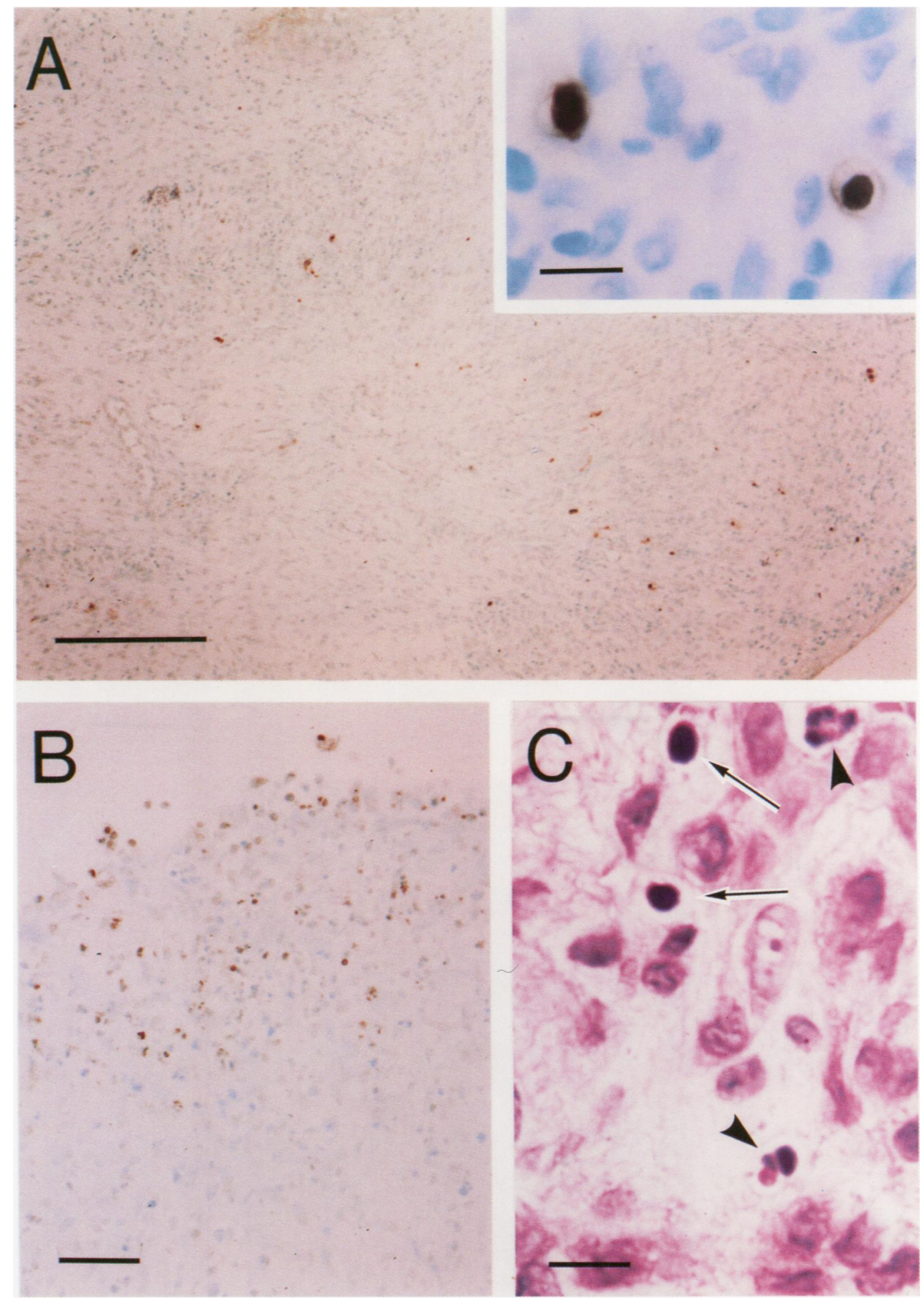

Figure 1 Apoptosis of synovial cells in rheumatoid arthritis: synovia from patient 7 (A (inset: higher magnification view)) and patient 11 (B), stained by in situ nick end labelling (ISNEL). Note different distribution of ISNEL positive cells between $\boldsymbol{A}$ (distributed sparsely within the sublining layer) and $\boldsymbol{B}$ (clustered in the superficial layer of synovial lining cells). C: Haematoxylin and eosin staining in patient 11. Note apoptosis specific morphological changes, including halo ring formation, eosinophilic change of the cytoplasm, chromatin condensation (arrow), and nuclear fragmentation (arrow head). Bars represent: $\boldsymbol{A}-500 \mu \mathrm{m}$; inset $10 \mu \mathrm{m} ; \boldsymbol{B}-100 \mu \mathrm{m} ; \boldsymbol{C}-10 \mu \mathrm{m}$.

it is generally accepted that the increased cellular content of the synovial membrane is the result of influx of bone marrow derived type A synoviocytes, rather than excessive intra-articular division of the synovial lining cells. ${ }^{1920}$ The finding in the present study of a low frequency of expression of PCNA (an accepted marker of cell division) in normal subjects supports the idea of an underlying low turnover of cell proliferation in normal synovial cells. In addition, the presence of PCNA positive cells clustered on the most superficial layers of the synovial lining cells is consistent with the findings of earlier studies ${ }^{21}$ demonstrating that hyperplasia of the RA synovium is partly a result of local proliferation of fibroblast-like synoviocytes.

In this study we investigated whether apoptosis is involved in the pathophysiology of RA synovium. Only two of 11 tissue specimens contained a small number of ISNEL positive cells. Furthermore, these cells were found in 


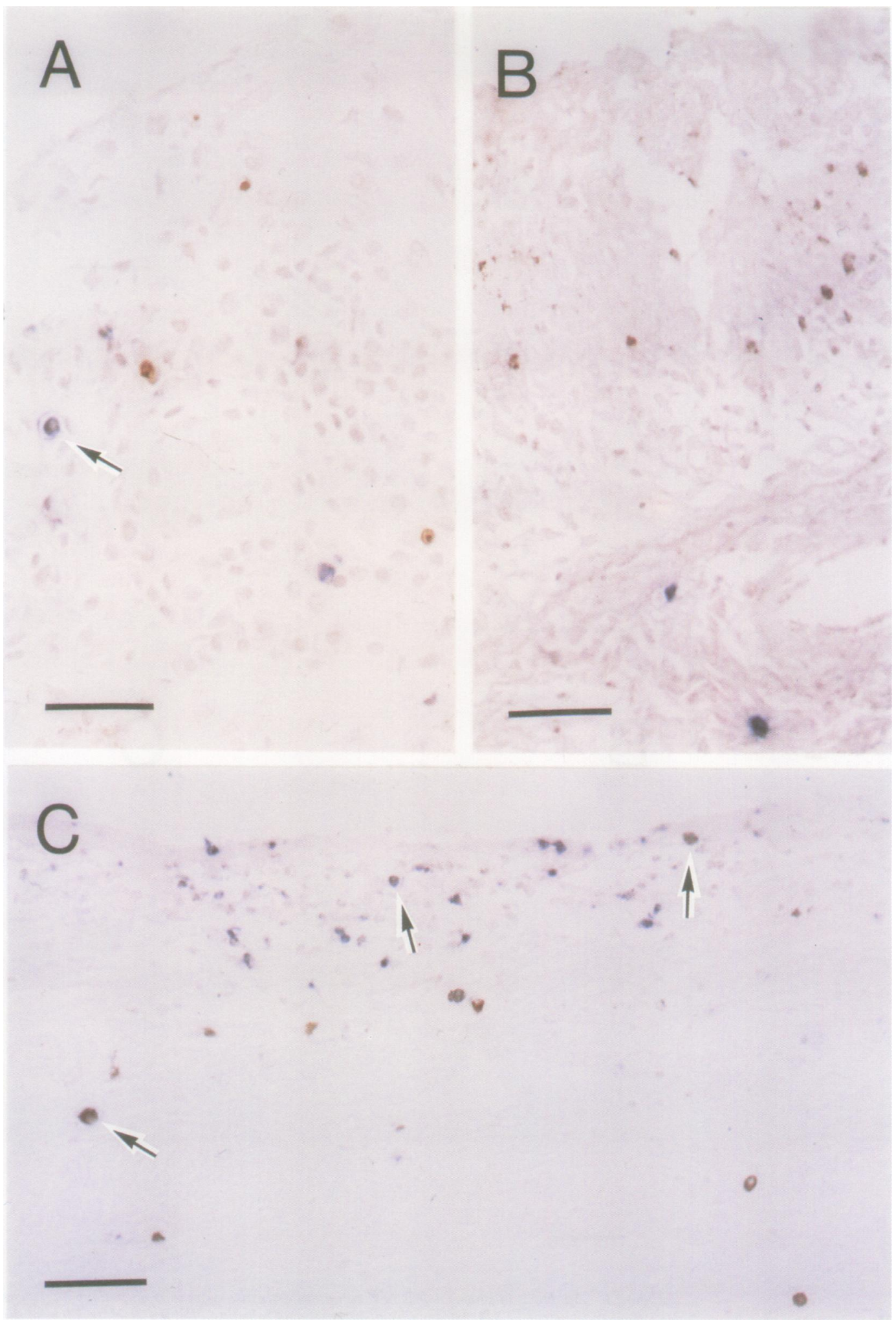

Figure 2 Combination of in situ nick end labelling (ISNEL) and immunohistochemistry. A: Synovia of patient 7 stained first by ISNEL (brown), then immunostained with CD68 antibody, a marker of macrophage (blue). Arrow indicates cell stained with both ISNEL and CD68 antibody. B: Synovium from patient 1 double stained with P21 $1^{\text {WAFICIPI }}$ (brown) and $p 53$ (blue). Note different localisation of cells expressing each protein. C: Double staining with p53 (brown) and CD68 (blue) in synovium of patient 2. Note several p53 positive cells also stained with CD68 (arrows). Bars represent $100 \mu \mathrm{m}$.

extremely limited regions of the synovial tissue. Although we could not identify the phenotype of apoptotic cells, it is likely that apoptosis occurs in sublining and synovial lining cells independent of the cell type. Recently, the presence of apoptosis in the RA synovium has been demonstrated by two groups of investigators, who demonstrated a proportion of ISNEL positive cells markedly greater than that found in the present study. ${ }^{22}{ }^{23}$ Nakajima et $a l^{22}$ reported that the RA synovium contained $30 \%$ of ISNEL positive cells, despite very few cells showing apoptosis specific morphological changes on electron microscopy. The reason for this discrepancy is unclear, but may reflect differences between the methods used for preparation of tissue specimensfreezing versus formalin fixation. ${ }^{23}$ However, 

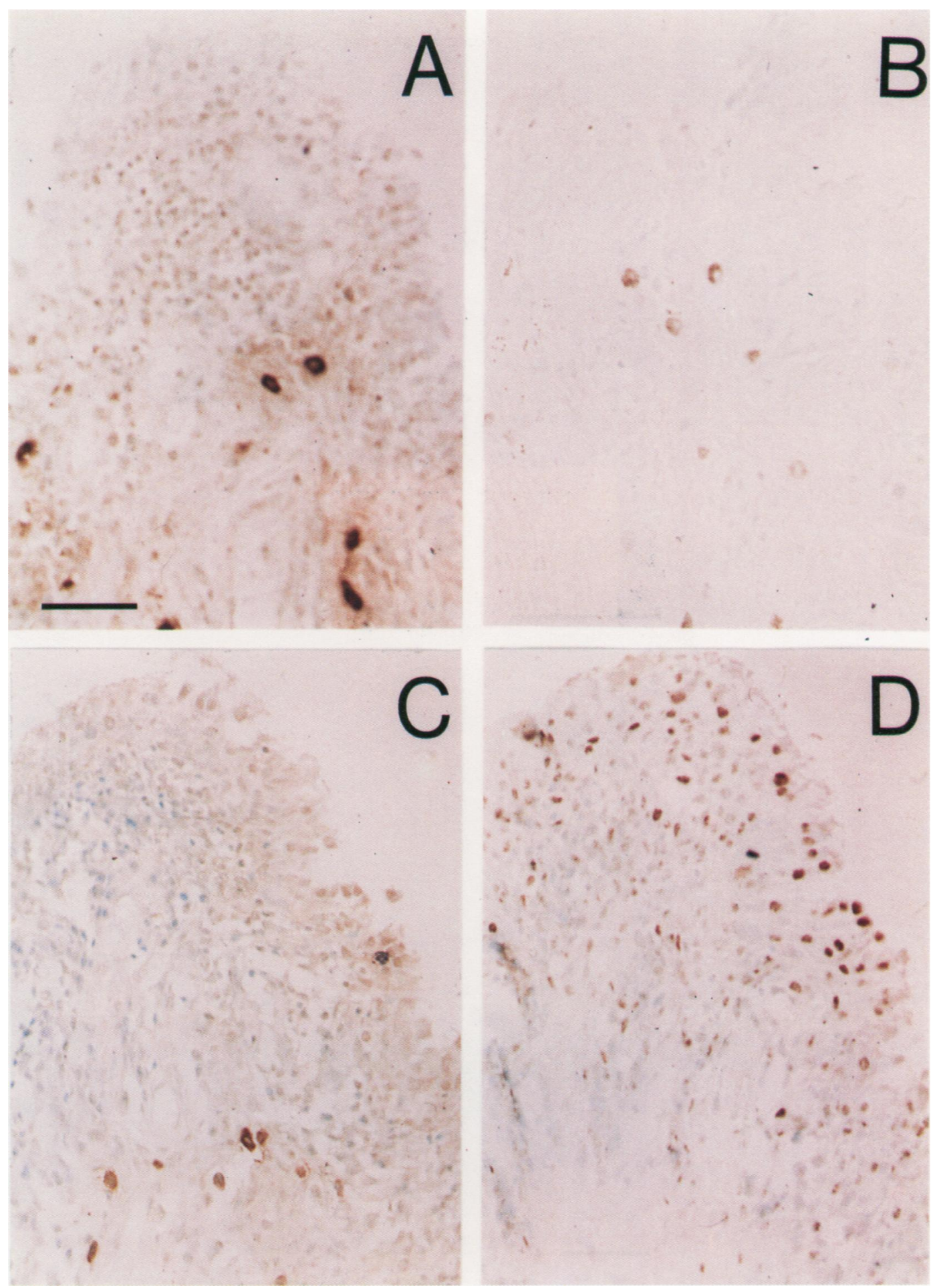

Figure 3 Immunolocalisation of $c-m y c, p 53, p 21^{\mathrm{WAF} / / C I P 1}$, and proliferating cell nuclear antigen (PCNA) proteins in $R A$ synovium. Consecutive sections from patient 8 stained with p21 $1_{\text {bAFICIPI }}(\boldsymbol{A}), p 53(\boldsymbol{B}), c-m y c(\boldsymbol{C})$, and PCNA (D)

antibodies. Note intense expression of $p 21^{W A F I C I P I}$ in cells containing large amounts of cytoplasm in the sublining layer $(\boldsymbol{A})$. Note also weak cytoplasmic staining for $p 53$ in the sublining cells $(\boldsymbol{B})$. Expression of c-myc also limited to the sublining cells (C). PCNA expressed predominantly in synovial lining cells with intranuclear staining (D). Bar in $\boldsymbol{A}$ represents $100 \mu m$.

the experimental procedure used in the present study was performed with appropriate positive control tissues such as the thymus and large intestine, and morphological changes characteristic of apoptosis were observed simultaneously with the detection of ISNEL positive cells, indicating that the frequency of ISNEL positive cells found in our study reflected the true level of apoptosis in the RA synovium. We also attempted to detect DNA fragmentation by electrophoresis on agarose gel and identified apoptosis specific morphological changes by electron microscopy. However, no evidence of apoptosis was detected, probably because of the small number of apoptotic cells (data not shown).

We found that c-myc, p53, and p2 $1^{\mathrm{WAF} 1 / \mathrm{CIP} 1}$ were overexpressed in the sublining cells of RA. Although expression of c-myc in synovial lining cells has been reported, ${ }^{24}$ expression was limited to the sublining cells in our study. Because of the limited number of antibodies available for double staining, we could not make a detailed comparison of the localisation 


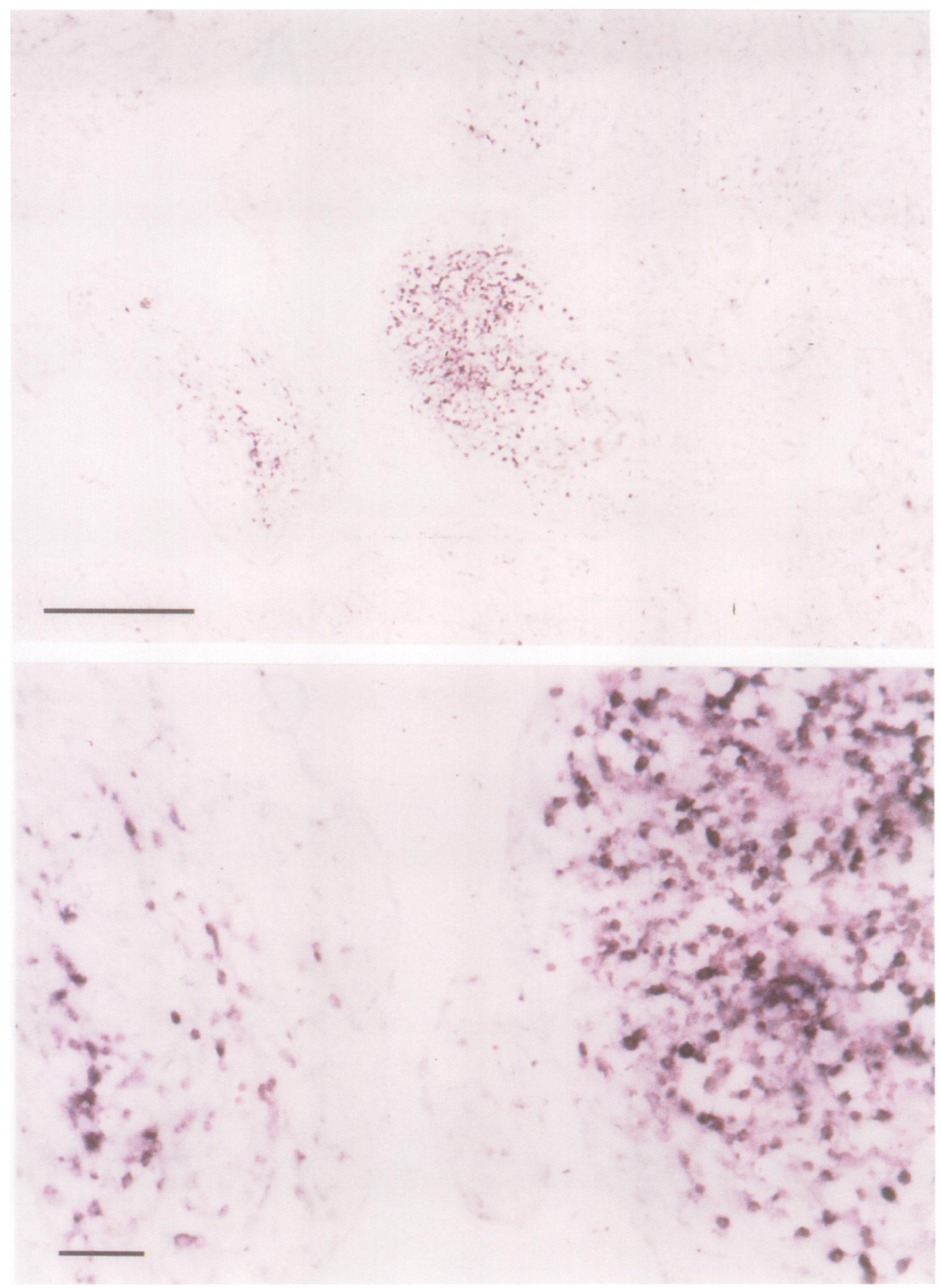

Figure 4 Immunohistochemical staining for Bcl-2 in RA synovium of patient 8, stained with Bcl-2 antibody. Note intense cytoplasmic expression of Bcl-2 protein in the infiltrated lymphocytes. Faint but distinct expression also observed in sublining cells and stromal cells within the lymphoid follicles. Lower panel is a higher magnification view of upper panel: bars represent $500 \mu \mathrm{m}$ and $100 \mu \mathrm{m}$, respectively.

of the expression of these proteins; however, these markers seem unlikely to be overexpressed simultaneously or to be limited to macrophage-like cells. While c-myc protein was initially identified as an oncogene, ${ }^{25}$ it has since been shown to induce apoptosis or cell cycle arrest. ${ }^{26}$ In contrast, stimulation of p53 protein expression occurs in response to DNA damage, and triggers cell cycle arrest or apoptosis via c-myc. ${ }^{27-29}$ In addition, p $21^{\text {WAF1/CIP1 }}$ inhibits cell cycle progression by suppressing cyclin/cyclin dependent kinase activity in p53 dependent and independent pathways. ${ }^{30-33}$ In the two ISNEL positive tissue samples, we compared the localisation of these proteins with that of ISNEL positive cells, to determine if they represented intermediate molecules implicated in apoptosis; however, their immunolocalisation differed considerably from that of ISNEL positive cells or morphologically apoptotic cells, and we thus consider that overexpression of these proteins does not implicate them in the apoptotic process. Instead, they might be expressed in association with cell cycle arrest rather than apoptosis, and it is possible that synovial cells may select cell cycle arrest, rather than initiating the apoptotic process, by expressing these proteins. There 
may be other, as yet unknown, functional roles for these proteins-for example, cell differentiation. ${ }^{34}$ In support of this concept, widespread distribution of $\mathrm{p} 21^{\text {WAF } 1 / C P 1} 1$ has been demonstrated in fetal and adult tissues. ${ }^{34} 35$

Our findings confirm those of previous studies $^{23}$ demonstrating that the $\mathrm{Bcl}-2$ protein was expressed particularly in infiltrated lymphocytes and in some RA synovial sublining cells in which apoptosis was not pronounced. As Bcl-2 acts as an inhibitor of apoptosis through the antioxidant pathway, ${ }^{36}{ }^{37}$ synovial cells expressing Bcl-2 may resist apoptosis in response to a number of stimuli. Such stimulation may be triggered by several factors, such as cytokines, free radicals, and nitrogen oxide, present at high levels in RA synovial fluid. ${ }^{38}$ In this regard, our finding that infiltrated lymphocytes did not undergo apoptosis may support an earlier hypothesis implicating failure of B cell death in the pathogenesis of RA. ${ }^{39}$ Although we did not identify the phenotype of infiltrated lymphocytes, overexpression of $\mathrm{Bcl}-2$ protein may increase the threshold for apoptosis, thus playing a key part in controlling the proportion of cells in the RA synovium..$^{40}$ Further studies are necessary to verify this assumption.

Considered together, our findings suggest that apoptosis can occur in RA synovial cells, but its frequency is extremely low compared with previous reports. We consider that apoptosis of the synovial tissue may tend to be suppressed by overexpression of Bcl-2, and that proliferated synovial tissue in RA may, indeed, fail to trigger apoptosis because it expresses Bcl-2. Although no significant relationship was found in the present study between apoptosis and disease duration or activity, it is possible that apoptosis may have a key role in synovial cell death occurring during the natural history of RA, and that it may be responsible for rice body formation or the disappearance of proliferated synovium in the late remission phase.

We wish to thank $M$ Tokunaga for the excellent preparation of histological sections, and Dr Y Yoshihara (Department of Orthopaedic Surgery, Kawatana National Hospital, Nagasaki) for his cooperation in collecting the tissue samples. We also for his cooperation in collecting the tissue samples. We also
thank Dr F G Issa (Department of Medicine, University of thank Dr F G Issa (Department of Medicine, University of
Sydney, Sydney, Australia) for critical reading and editing of the manuscript.

1 Kerr J F R, Wyllie A H, Currie A R. Apoptosis: a basic biological phenomenon with wide-ranging implications in tissue kinetics. Br f Cancer 1972; 26: 239-57.

2 Majno G, Joris L. Apoptosis, oncosis, and necrosis: a preview of cell death. Am $\mathcal{F}$ Path 1995; 146: 3-15.

3 Wylie A H. Glucocorticoid-induced thymocyte apoptosis is associated with endogenous endonuclease activation. Nature 1980; 284: 555-6.

4 Wylie A H, Morris R G, Smith A L, Dunlop D. Chromatin cleavage in apoptosis: association with condensed chromatin morphology and dependence on macromolecular synthesis. F Pathol 1984; 142: 67-77.

5 Gavrieli Y, Sherman Y, Ben-Sasson S A. Identification of programmed cell death in situ via specific labeling of nuclear DNA fragmentation. $f$ Cell Biol 1992; 119: 493-501.

6 Carson D A, Ribeiro J M. Apoptosis and disease. Lancet 1993; 341: $1251-4$

7 Thompson C B. Apoptosis in the pathogenesis and treatment of disease. Science 1995; 267: 1456-62.

8 Fox R I, Kang H. Structure and function of synoviocytes. In: McCarty D J, Koopman W J, eds. Arthritis and allied conditions. Pennsylvania: Lea \& Febiger, 1993; 263-78.

9 Case J P, Lafyatis R, Remmers E F, Kumkumian G K Wilder R L. Transin/stromelysin expression in rheumatoid synovium: a transformation-associated metallo- proteinase secreted by phenotypically invasive synoviocytes. Am ₹ Path 1989; 135: 1055-64.

10 Pelletier J P, Faure M P, DiBattista J A, Wilhelm S, Visco D, Pelletier J M. Coordinate synthesis of stromelysin, interleukin-1, and oncogene proteins in experimental osteoarthritis. Am 7 Path 1993; 142: 95-105.

11 Berg E, Wainwright R, Barton B, Puchtler H, McDonald T. On the nature of rheumatoid rice bodies: an immunological, histochemical and electronmicroscopic study. Arthritis Rheum 1977; 20: 1343-9.

12 McCarty D J, Cheung H S. Origin and significance of rice bodies in synovial fluid. Lancet 1982; 2: 715.

13 Fassbender $\mathrm{H}$ G. Is pannus a residue of inflammation? Arthritis Rheum 1984; 27: 956-7.

14 Arnett F C, Edworthy S M, Bloch D A, et al. The American Rheumatism Association 1987 revised criteria for the classification of rheumatoid arthritis. Arthritis Rheum 1988; 31: 315-24.

15 Kinouchi T, Saiki S, Naoe T, et al. Correlation of c-myc expression with nuclear pleomorphism in human renal expression with nuclear pleomorphism in hum

16 Schmitz G G, Walter T, Seibl R, Kessler C. Nonradioactive labeling of oligonucleotides in vitro with the hapten digoxigenin by tailing with terminal transferase. Anal Biochem 1991; 192: 222-31.

17 Mohr W, Beneke G, Mohing W. Proliferation of synovial lining cells and fibroblasts. Ann Rheum Dis 1975; 34: 219-24.

18 Henderson B, Glynn L E, Chayen J. Cell division in the synovial lining in experimental allergic arthritis: proliferation of cells during the development of chronic proliferation of cells during the developm
arthritis. Ann Rheum Dis 1982; 41: 275-81.

19 Krey P R, Cohen A S, Smith C B, Finland M. The human fetal synovium. Histology, fine structure and changes in organ culture. Arthritis Rheum 1971; 14: 319-25.

20 Edwards J C W, Willoughby D A. Demonstration of bone marrow-derived cells in synovial lining by means of giant intracellular granules as genetic markers. Ann Rheum Dis 1982; 41: 177-82.

21 Qu Z, Garcia C H, O'Rourke L M, Planck S R, Kohli M, Rosenbaum J T. Local proliferation of fibroblast-like synoviocytes contributes to synovial hyperplasia. Results of proliferating cell nuclear antigen/cyclin, c-myc, and of proliferating cell nuclear antigen/cyclin, c-myc, and 37: 212-20.

22 Nakajima T, Aono H, Hasumura $T$, et al. Apoptosis and functional fas antigen in rheumatoid arthritis synoviocytes. Arthritis Rheum 1995; 38: 485-91.

23 Firestein G S, Yeo M, Zvaifler N J. Apoptosis in rheumatoid arthritis synovium. $\mathcal{f}$ Clin Invest 1995; 96: 1631-8.

24 Trabandt A, Aicher W K, Gay R E, et al. Expression of the collagenolytic and ras-induced cysteine proteinase cathepsin L and proliferation-associated oncogenes in synovial cells of MRL/I mice and patients with rheumatoid arthritis. Matrix 1990; 10: 349-61.

25 Colby W W, Chen E Y, Smith D H, Levinson A D Indentification and nucleotide sequence of a human locus homologous to the v-myc oncogene of avian myelocytohomologous to the v-myc oncogene of avian mye

26 Evan G I, Wyllie A H, Gilbert C S, et al. Induction of apoptosis in fibroblasts by c-myc protein. Cell 1992; 69: 119-28.

27 Yonishi-Rouach E, Grunwald E D, Wilder S, et al. p-53 mediated cell death: relationship to cell cycle control. Mol Cell Biol 1993; 13: 1415-23.

28 Maltzman W, Czyzyk L. UV irradiation stimulates levels of p53 cellular tumor antigen in nontransformed mouse cell. Mol Cell Biol 1984; 4: 1689-94.

29 Hermeking H, Eick D. Mediation of c-myc-induced apoptosis by p53. Science 1994; 265: 2091-3.

30 Eizenberg O, Elman A F, Gottlieb E, Oren M, Rotter V, Schwaltz M. Direct involvement of p53 in programmed Schwaltz $M$. Direct involvement of p53 in programmed
cell death of oligodendrocytes. EMBO $f$ 1995; 14: cell death.

31 El-Deiry W S, Tokino T, Velculescu V E, et al. Waf-1, a potential mediator of p53 tumor suppression. Cell 1993; 75: 817-25.

32 Xiong Y, Hannon G J, Zhang H, Casso D, Kobayashi R, Beach D. p21 is a universal inhibitor of cyclin kinases. Nature 1993; 366: 701-4.

33 Harper J W, Adami G R, Wei N, Keyomarsi K, Elledge S. The p21 Cdk-interacting protein Cipl is a patent inhibitor of $\mathrm{Gl}$ cyclin-dependent kinsases. Cell 1993; 75: 805-16.

34 Parker S B, Eichele G, Zhang P, et al. p53-independent expression of p21Cipl in muscle and other terminally differentiating cells. Science 1995; 267: 1024-7.

35 EI-Deiry W S, Tokino T, Waldman T, et al. Topological control of $\mathrm{p} 21^{\text {WAFI/CIP1 }}$ expression in normal and neoplasmic tissues. Cancer Res 1993; 55: 2910-9.

36 Korsmeyer S J. Bcl-2 initiates a new category of oncogenes: regulators of cell death. Blood 1992; 80: 879-86.

37 Hockenbery D $M$, Oltvai Z N, Yin X M, Milliman C L Korsmeyer S J. Bcl-2 functions in an antioxidant pathway to prevent apoptosis. Cell 1993; 75: 241-51.

38 Poole A R. Cartilage in health and disease. In: McCarty D J Koopman $\mathrm{W}$ J, eds Arthritis and allied conditions. Pennsylvania: Lea \& Febiger, 1993; 279-333.

39 Edwards J C, Cambridge J. Is rheumatoid arthritis a failure of B cell death in synovium? Ann Rheum Dis 1995; 54: 696-700.

40 Vaux D L, Cory S, Adams J M. Bcl-2 promotes the surviva of haemopoietic cells and cooperates with c-myc to immortalize pre-B cells. Nature 1988; 335: 440-2. 